\title{
REFLEXÕES SOBRE OS IMPACTOS DA RESOLUÇÃO № 02/2019 NA FORMAÇÃO INICIAL DOCENTE
}

\section{REFLECTIONS ON THE IMPACTS OF RESOLUTION Nº 02/2019 ON INITIAL TEACHER EDUCATION}

\author{
Flavia Wegrzyn Magrinelli Martinez ${ }^{1}$ \\ Nathalia Cristina Vidal ${ }^{2}$ \\ Analígia Miranda da Silva ${ }^{3}$
}

\begin{abstract}
RESUMO: A formação docente no Brasil é lócus de disputas e relações de poder. A partir de uma abordagem qualitativa, este artigo objetiva discutir e fomentar o debate, sobre a concepção de formação de professores presente na Resolução no 02/2019 (BNC - Formação). Inferimos que a resolução alinha a formação docente para uma estrita reprodução de competências impostas pela BNCC e BNC-Formação, o que retira os professores da centralidade de seu trabalho e restringe a intelectualidade da profissão docente. Verificamos que, além da perspectiva alinhada às competências, a concepção de formação docente da Resolução n $n^{\circ}$ 02/2019 se aporta em uma dimensão técnica e instrumental, pois sobreleva a prática e minimiza a teoria. Tal situação leva à uma padronização do trabalho docente e à redução da prática para o sentido utilitário a partir do domínio de conteúdos e conhecimentos técnicos. Assim, a concepção de formação docente contida nos excertos do documento demonstra um viés técnico, praticista e utilitarista, envergando a educação brasileira para um indistinguível retrocesso que implica ainda mais na profunda precarização do trabalho docente.
\end{abstract}

PALAVRAS-CHAVES: Formação Inicial Docente. BNC-Formação. Competências.

\begin{abstract}
Teacher training in Brazil is a locus of disputes and power relations. From a qualitative approach, this article aims to discuss and encourage debate on the concept of teacher education present in Resolution $02 / 2019$ (BNC - Training). We infer that the resolution aligns teacher education to a strict reproduction of competencies imposed by the BNCC and BNC-Formação, which removes teachers from the centrality of their work and restricts the intellectuality of the teaching profession. We found that, in addition to the perspective aligned with the competencies, the conception of teacher education in Resolution $n$ 을 $02 / 2019$ is supported by a technical and instrumental dimension, as it overemphasizes practice and minimizes theory. This situation leads to a standardization of the teaching work and the reduction of practice to a utilitarian sense based on the mastery of contents and technical knowledge. Thus, the conception of teacher education contained in the excerpts of the document shows a technical, practical, and utilitarian bias, leading Brazilian education to an indistinguishable regression that further implies the profound precariousness of the teaching work.
\end{abstract}

KEYWORDS: Initial Teacher Education. BNC-Formação. Competencies.

\footnotetext{
1 Universidade Estadual do Norte do Paraná, Brasil. E-mail: fwmartinez@uenp.edu.br

(1) https://orcid.org/0000-0003-3540-4032

2 Universidade Estadual do Norte do Paraná, Brasil. E-mail: nathaliavidal@outlook.com

https://orcid.org/0000-0001-8969-3453

3 Universidade Federal de Mato Grosso do Sul, Brasil. E-mail: analigia.miranda@ufms.br

(iD) https://orcid.org/0000-0002-3232-323X
}

- Informações completas da obra no final do artigo 


\section{ENSIN@UFMS 2021}

ISSN 2525-7056

\section{Introdução}

A formação docente no Brasil é lócus de disputas e relações de poder. No Brasil, após o Golpe de 2016, o campo educacional sofre profundas mudanças, e emerge uma tentativa de desconstrução da valorização simbólica do professor perante a sociedade. As instituições formativas e os professores sofrem perseguições (como vimos com o Projeto "Escola sem Partido") e passam a ocorrer uma série de medidas que restringem o direito à educação pública e precarizam o trabalho do professor, como o descaso com 0 financiamento da Educação Básica (FUNDEB); o desinvestimento em estratégias para alcançar as metas do Plano Nacional de Educação (PNE 2014-2024); o desmonte de políticas educacionais, como a contrarreforma do Ensino Médio, e a aprovação da Base Nacional Curricular Comum (BNCC), caracterizada pelo empobrecimento e pelo esvaziamento curricular, que direciona sua ação a aspectos utilitários e fragmentados sem considerar a totalidade complexa que envolve a ação profissional docente.

Na mesma esteira, ocorre a revogação impositiva da Resolução CNE/CP 2/2015 e a aprovação da Resolução CNE/CP 2/2019, que define a Formação Inicial de Professores para a Educação Básica e institui a Base Nacional Comum para a Formação Inicial de Professores da Educação Básica (BNC-Formação), tendo como referência a implementação da BNCC.

As reformas educacionais, em sua face opressora, coagem os professores ao restringir a sua atuação intelectual em razão de que "[...] muitas das recomendações que surgiram no atual debate ignoram o papel que os professores desempenham na preparação dos aprendizes para serem cidadãos ativos e críticos [...]" (GIROUX, 1997, p. 157). Consideramos que há esforços políticos que, a partir da implementação de currículos controversos, descaracterizam o trabalho do professor, reduzindo-os à reprodutores de competências, e os "[...] seus princípios e fundamentos que continuam a causar desdobramentos nefastos na organização da educação nacional em função da Base Nacional Comum Curricular (BNCC)" (RODRIGUES, et al., 2021).

Diante de tais desdobramentos, partir de uma abordagem qualitativa, este artigo objetiva discutir e fomentar o debate, sobre a concepção de formação de professores presente na Resolução no 02/2019 (BNC - Formação) e está estruturado em três partes. Inicialmente discutimos sobre a formação inicial de professores; na sequência, sobre o conceito do professor intelectual com base teórica ancorada em Giroux (1997), e, por fim, 
analisamos os pontos de tensões presentes na Resolução nº 02/2019 (BNC-Formação) que inviabilizam uma formação intelectual e autônoma do professor.

\section{Formação Inicial de Professores e a BNC-Formação: breves reflexões}

A discussão crítica sobre os cursos de formação de professores é necessária para a fomentação de um espaço de lutas e embates pela defesa da autonomia, pela intelectualidade e pela valorização da profissão docente. Como propõe Nóvoa (1992), a formação docente deve propiciar aos professores os meios para o pensar autônomo e ampliar o horizonte do sentido crítico-reflexivo da sua atuação profissional. Tal perspectiva contrapõe o que a história da docência no Brasil revela quando demonstra nitidamente os modelos de sociedade e de formação humana que impõem o viés capitalista na educação, transformando o sistema educacional em instrumento de conservação social, uma vez que difunde as forças ideológicas que sustentam as ordens políticas, sociais e econômicas vigentes. Não obstante, o Estado, como controlador da formação docente, incute a certificação de competências (elemento que aprofundaremos no decorrer do artigo) como um dos processos de regulação e avaliação proposto pelo Estado, o que significa o controle da formação e atuação profissional do professor (BRZEZINSKI, 2008).

Assim, as políticas educacionais são permeadas por um campo de conflitos entre a sociedade política, que supõe a qualidade social, mas age pela qualidade total $^{4}$, e a sociedade civil, que almeja e necessita da qualidade social na formação docente para a Educação Básica. Nesse campo de tensões, o Estado regulamenta o modelo de qualidade total, ou seja, de competências e de excelência, visando atingir aspectos econômicos e produtivos na formação inicial de professores (BRZEZINSKI, 2008). Com uma concepção mercadológica, tal modelo de qualidade total propaga uma formação de professores aligeirada que, para Brzezinski (2008, p. 1152), "[...] reduz a quantidade de horas e a qualidade acadêmica, científica e cultural, porque o aligeiramento é induzido pela volatilidade das qualificações requeridas pelo mercado [...]".

O Estado "[...] propugna a cultura da produção de saberes instrumentais e utilitários para a preparação de mão de obra tal como exigida pelo sistema capitalista" (BRZEZINSKI,

\footnotetext{
4 Pressupõe a transposição de técnicas empresariais para a educação, com a intencionalidade administrativa de se estabelecer uma relação de custo $X$ qualidade. Compreendemos que essa perspectiva é regulada pelo viés mercadológico e tem, por finalidade, a mercantilização da educação.
} 
2008 , p. 1151), sustentado pela tendência neotecnicista da educação e neocapital humano, levando as competências para a fundamentação da formação inicial de professores. Nesse sentido, o trabalho docente é minimizado a um teor técnico e prático, que desconsidera o verdadeiro papel do professor enquanto profissional intelectual. Negligencia-se, portanto, o verdadeiro sentido da profissão docente ao estabelecer um direcionamento estritamente esvaziado de criticidade, reflexão, intelectualidade e produção de conhecimentos para a formação de professores. Compreendemos que os problemas que ocorrem no contexto real da profissão docente não são predeterminados, ou seja, não são resumidos a processos instrumentais. Como nos aponta Nóvoa (1992) as situações que ocorrem derivam de perguntas únicas que exigem respostas únicas, sendo que a resposta é uma formação que garanta o desenvolvimento de uma práxis reflexiva. Ademais, existe uma lógica técnica em detrimento à práxis reflexiva na formação de professores. Brzezinski $(2008$, p. 1153) aponta que

Não é difícil identificar o produto desta lógica (de)formação: o preparo do professor
centra-se no desenvolvimento de competências para o exercício técnico-
profissional, consistindo, pois, em um preparo prático, simplista e prescritivo,
baseado no aprendizado "imediato" do que vai ensinar, a fim de resolver problemas
do cotidiano da escola [...]

A formação inicial de professores conta com diferentes dimensões, possibilitando a reflexão em torno da Educação Básica. Portanto, é inerente caminhar para a ressignificação de concepções e práticas que ainda se aportam em um viés instrumental. A teoria e a prática precisam estar articuladas durante o percurso da formação inicial, de maneira a constituir a unidade teoria-prática, constituindo, assim, em conhecimentos e práticas para a construção da emancipação profissional.

Desse modo, defendemos que a formação docente precisa ser fundamentada "[...] em uma concepção sócio-histórica e de caráter emancipador, comprometida com as transformações sociais necessárias para a superação do atual sistema político social [...]" (ANFOPE, 2021, p. 26). A unidade teoria-prática deve atravessar todo o curso de formação, tendo o trabalho coletivo e interdisciplinar como centralidade do trabalho docente, a fim de promover o compromisso social, político e ético do educador, de mobilizar a participação nas lutas e nos movimentos sociais (ANFOPE, 2021), visto que a formação inicial de professores é um momento-chave para a preparação dos profissionais da educação, que 
precisa ser fundamentada a partir de uma sólida proposta formativa, possibilitando a formação de agentes intelectuais e transformadores (GIROUX, 1997).

\section{Professores, sujeitos de intelectualidade e saberes}

No cenário político atual, as reformas educacionais e curriculares têm refletido diretamente no trabalho do professor, pois como bem expressa Giroux (1997, p. 157), são reformas que "[...] ignoram a inteligência, julgamento e experiência que os professores poderiam oferecer em tal debate [...]" (GIROUX, 1997, p. 157), o que gera a depreciação das decisões do corpo docente diante das estruturas de poder.

Como aponta Giroux (1997), frente às crises educacionais, emerge a necessidade de os professores participarem ativamente do debate público sobre os aspectos inerentes ao seu trabalho e ocuparem a posição de intelectuais, em decorrência da especificidade do trabalho docente, que vai muito além da reprodução de práticas e técnicas, já que trata-se de um "[...] um espaço de produção, de transformação e de mobilização de saberes que lhe são próprios. [...]" (TARDIF, 2014, p. 237).

Giroux (1997), ao compreender e defender o professor enquanto intelectual e ao conceituar que "[...] o uso da mente é uma parte geral de toda atividade humana, nós dignificamos a capacidade humana de integrar o pensamento e a prática, e assim destacamos a essência do que significa encarar os professores como profissionais reflexivos [...]" (GIROUX, 1997, p. 161), aponta que o exercício do trabalho docente fundamenta-se a partir da unidade teoria-prática e, portanto, o processo formativo do professor deve também ser fundamentado com base nessa perspectiva.

O professor como sujeito do conhecimento, que possui saberes específicos inerentes à profissão, deve ter um processo de participação ativo no que diz respeito ao seu trabalho e, desta feita, os seus interesses, os pontos de vista e as suas necessidades devem ser consideradas (TARDIF, 2014). É, então, basilar reconhecer o professor como "[...] sujeitos do conhecimento e não simplesmente como espíritos virgens aos quais nos limitamos a fornecer conhecimentos disciplinares e informações procedimentais [...]" (TARDIF, 2014, p. 242). Dessa forma, o professor precisa ser compreendido enquanto intelectual do seu trabalho, e a formação para tal deve ocorrer durante todo o seu percurso profissional, especialmente no espaço da formação inicial. 
Por conseguinte, Giroux (1997) propõe que, para reestruturar a natureza da atividade docente, é preciso compreender os professores como intelectuais transformadores, o que contribui para pensar no trabalho docente como intelectual, em oposição à redução do trabalho ao instrumental e técnico. Portanto, a elucidação de concepções ideológicas se faz necessária logo que a profissão docente é envolta pelas esferas políticas, econômicas e sociais, pois, "[...] em resumo, as escolas não são locais neutros e os professores não podem tampouco assumir a postura de serem neutros" (GIROUX, 1997, p. 162). Nesse sentido, para a condição de intelectual transformador, é indispensável tornar o pedagógico mais político, agregando a escolarização na esfera política ao travar embates para superar as desigualdades diante das relações de poder, assim como também tornar o político mais pedagógico, aplicando a pedagogia para alcançar os interesses políticos de intenção emancipatória que considerem os sujeitos como críticos e ativos (GIROUX, 1997).

Diante desse contexto, para compreender as condições que envolvam o trabalho docente, é determinante analisar as forças ideológicas e materiais expressas pelas e nas reformas curriculares que, nos últimos anos, têm favorecido a proletarização do trabalho docente a partir da compreensão dos professores para a posição de meros técnicos, "[...] cuja função, então, torna-se administrar e implementar programas curriculares, mais do que desenvolver ou apropriar-se criticamente de currículos que satisfaçam objetivos pedagógicos específicos [...]" (GIROUX, 1997, p. 158). Observamos um movimento que descaracteriza inteiramente $\mathrm{o}$ trabalho docente ao reduzir a função do professor a um aplicador de técnicas, anulando o teor crítico e reflexivo na medida em que se desenvolvem aspectos instrumentais e pragmáticos na formação docente. Tal vertente abrange um intento que fragiliza o ensino, sendo uma forte ameaça para a educação pública e para a profissão docente, dado que o professor perde a sua autonomia, pois ocorre "[...] o apelo pela separação de concepção de execução; a padronização do conhecimento escolar com o interesse de administrá-lo e controlá-lo [...]" (GIROUX, 1997, p. 159), além de priorizar aspectos práticos e desvalorizar a criticidade e intelectualidade dos professores ao antepor a reprodução de práticas preestabelecidas e dirigidas e ao negar a necessidade do pensamento crítico do professor, o que torna a formação docente muito fragilizada.

Assim, uma proposta pragmática de formação de professores não possibilita uma formação docente, autônoma e sólida, mas viabiliza uma proposta curricular prescritiva, pautada em regulamentações que determinam conteúdos padronizados por currículos que 
legitimam as pedagogias de gerenciamento. O que vemos é que a organização da "[...] vida escolar em torno de especialistas em currículo, instrução e avaliação, aos quais se reserva a tarefa de concepção, ao passo que os professores são reduzidos à tarefa de implementação [...]" (GIROUX, 1997, p. 160), o que conduz os professores a terem acesso a conhecimentos padronizados que serão sistematicamente aplicados, controlados e restritos a práticas igualitárias e previsíveis, que retiram do trabalho docente o caráter intelectual da profissão. O viés pragmático, mecanizado e técnico do trabalho dos professores representa um retrocesso para a formação docente, o que reflete diretamente na profissão. Desta feita, defendemos uma proposta de formação docente que possibilite a constituição de intelectuais transformadores da realidade.

\section{A Resolução nº 02/2019}

Para compreender a proposta formativa presente na Resolução CNE/CP nำ2, de 20 de dezembro de 2019, é necessário entender o contexto da atual conjuntura política e educacional, os pontos de tensões e as intenções que fomentaram esta discussão e subsistem no interior do documento. Com ênfase nas falácias e influências do neoliberalismo, houve uma expansão do setor privado na economia e na educação, o que possibilitou a privatização do setor público, pertencente ao Estado, e tem se constituído mecanismo de poder sob a consolidação do capitalismo na sociedade e para manutenção de hegemonias (RODRIGUES; PEREIRA; MOHR, 2020).

A sociedade capitalista intervém diretamente na formação docente por um conjunto de determinações que tange aos desdobramentos na educação, caracterizando a formação de professores na mira do capital. Assim, para compreender a formação docente no Brasil no momento atual, é preciso olhar para um conjunto de determinações impostas pelo contexto da sociedade capitalista, já que esta estabelece uma tríplice relação que influi expressamente nos cursos de formação, amplamente designados pela Organização Multilateral (OM), o Aparelho Privado de Hegemonia (APH) e o Aparelho de Estado (AE) que atuam sobre a escola como processos mediadores, circuncidando objetivos para assegurar a hegemonia burguesa (EVANGELISTA, 2021).

As pesquisas realizadas por Evangelista (2021) alegam que é considerável compreender que a OM propõe uma formação docente por meio das elaborações de intelectuais orgânicos que desenvolvem as políticas apoiadas na reprodução de interesses 
do capital. O APH é composto por organizações da sociedade civil da classe dominante capitalista, por instituições, por fundações, por organizações e por associações que definem as ações do aparelho privado a partir de uma concepção de educação tencionada por interesses econômicos, formados por uma hegemonia. E o AE conflui para uma ideia de formação docente para o preparo da força de trabalho simples, onde o professor se caracteriza como um sujeito propenso a duas forças opostas, dentre os interesses do capital e os da classe trabalhadora, por contradições que atravessam a docência no contexto político atual (EVANGELISTA, 2021).

Nesse cenário, a Resolução n 02/2019 foi promulgada pelo Conselho Nacional de Educação, que "Define as Diretrizes Curriculares Nacionais para a Formação Inicial de Professores para a Educação Básica e institui a Base Nacional Comum para a Formação Inicial de Professores da Educação Básica (BNC-Formação)." (BRASIL, 2019, p. 1), tendo como referência principal a BNCC.

A BNCC preconizava um novo projeto de educação, pois, em seu documento, já consta que "[...] influenciará a formação inicial e continuada dos educadores, a produção de materiais didáticos, as matrizes de avaliações e os exames nacionais que serão revistos à luz do texto homologado da Base" (BRASIL, 2017, p. 9). Delineou-se, assim, uma reconfiguração da Educação Básica no Brasil a partir de uma perspectiva contrária aos preceitos de emancipação, com uma proposta que valoriza e prioriza as áreas de conhecimento, os exames, as notas e os resultados, e desconsidera áreas das ciências humanas, a dimensão social e econômica. Nesta linha, como já prenunciava a BNCC:

A primeira tarefa de responsabilidade direta da União será a revisão da formação
inicial e continuada dos professores para alinhá-las à BNCC. A ação nacional será
crucial nessa iniciativa, já que se trata da esfera que responde pela regulação do
ensino superior, nível no qual se prepara grande parte desses profissionais. Diante
das evidências sobre a relevância dos professores e demais membros da equipe
escolar para o sucesso dos alunos, essa é uma ação fundamental para a
implementação eficaz da BNCC. (BRASIL, 2017, p. 21).

Ressalva-se a relação do termo "sucesso dos alunos" com o intento mercadológico para o ensino, e do professor enquanto um possibilitador deste sucesso a partir da "implementação eficaz" das competências da BNCC. E, na Resolução nº 02/2019, é explícita a intencionalidade de atender a BNCC, como podemos perceber no Capítulo I, parágrafo único, regendo que: 
As Diretrizes Curriculares Nacionais para a Formação Inicial em Nível Superior de Professores para a Educação Básica e a BNC-Formação têm como referência a implantação da Base Nacional Comum Curricular da Educação Básica (BNCC), instituída pelas Resoluções CNE/CP no 2/2017 e CNE/CP nº 4/2018. (BRASIL, 2019, p. 2).

Como resultado da adequação à BNCC, foi imposta uma nova resolução a fim de formar professores que pudessem "aplicar" os preceitos da BNCC que pudessem ser vigorados em todo o território nacional, e esta evidência se torna clara quando o Art. $2^{\circ}$ da Resolução n 02/2019 discorre que a formação de professores desenvolva as competências gerais da BNCC, que é determinada como:

[...] a mobilização de conhecimentos (conceitos e procedimentos), habilidades (práticas, cognitivas e socioemocionais), atitudes e valores para resolver demandas complexas da vida cotidiana, do pleno exercício da cidadania e do mundo do trabalho. (BRASIL, 2017, p. 8, grifo nosso).

As competências já subentendem o arraigamento do viés técnico a partir de procedimentos e habilidades práticas, intencionadas a corresponder às necessidades do mundo do trabalho. Em concomitância, o Art. $3^{\circ}$ impõe que, no mesmo sentido das competências gerais da BNCC, o licenciando deverá desenvolver as competências gerais docentes. $E$, no respectivo parágrafo único, exprime as competências específicas e habilidades da BNC-Formação, que, como decorrido no Art. $4^{\circ}$, incluem as dimensões para a ação docente:

I - conhecimento profissional;

II - prática profissional; e

III - engajamento profissional.

$\S 1^{\circ}$ As competências específicas da dimensão do conhecimento profissional são as seguintes:

I - dominar os objetos de conhecimento e saber como ensiná-los;

II - demonstrar conhecimento sobre os estudantes e como eles aprendem;

III - reconhecer os contextos de vida dos estudantes; e

IV - conhecer a estrutura e a governança dos sistemas educacionais.

$\S 2^{\circ}$ As competências específicas da dimensão da prática profissional compõem-se pelas seguintes ações:

I - planejar as ações de ensino que resultem em efetivas aprendizagens;

II - criar e saber gerir os ambientes de aprendizagem;

III - avaliar o desenvolvimento do educando, a aprendizagem e o ensino; e

IV - conduzir as práticas pedagógicas dos objetos do conhecimento, as competências e as habilidades.

$\S 3^{\circ}$ As competências específicas da dimensão do engajamento profissional podem ser assim discriminadas:

I - comprometer-se com o próprio desenvolvimento profissional;

II - comprometer-se com a aprendizagem dos estudantes e colocar em prática o princípio de que todos são capazes de aprender;

III - participar do Projeto Pedagógico da escola e da construção de valores democráticos; e 
IV - engajar-se, profissionalmente, com as famílias e com a comunidade, visando melhorar o ambiente escolar. (BRASIL, 2019, p. 2, grifo nosso).

Já o Art. $7^{\circ}$ impõe a formação inicial de professores para a Educação Básica de acordo com as aprendizagens da BNCC e reconhece a formação de professores como "[...] um conjunto de conhecimentos, habilidades, valores e atitudes, que estão inerentemente alicerçados na prática [...]" (BRASIL, 2019, p. 4) e, para tanto, a resolução apresenta uma lista de competências e habilidades que devem embasar a formação docente.

Põe-se em evidência o teor do praticismo, que preconiza a ação prático-utilitária, priorizando a prática em detrimento da teoria nos cursos de formação docente "[...] por meio de estágios que enfoquem o planejamento, a regência e a avaliação de aula [...]" (BRASIL, 2019 , p. 4), a partir da parceria com instituições de ensino "[...] para o planejamento, a execução e a avaliação conjunta das atividades práticas previstas na formação do licenciando." (BRASIL, 2019, p. 4). Além disso, há uma exacerbação da avaliação do processo formativo em larga escala em concomitância aos preceitos de atingir resultados mediante competências, restringindo o currículo a padrões impostos.

A resolução ainda apresenta uma proposta de organização curricular dos cursos superiores para a formação docente, como podemos visualizar no Capítulo IV, que organiza o curso em três grupos, com carga horária mínima de 3.200 horas:

Art. 11. A referida carga horária dos cursos de licenciatura deve ter a seguinte distribuição:

I - Grupo I: 800 (oitocentas) horas, para a base comum que compreende os conhecimentos científicos, educacionais e pedagógicos e fundamentam a educação e suas articulações com os sistemas, as escolas e as práticas educacionais.

II - Grupo II: 1.600 (mil e seiscentas) horas, para a aprendizagem dos conteúdos específicos das áreas, componentes, unidades temáticas e objetos de conhecimento da BNCC, e para o domínio pedagógico desses conteúdos.

III - Grupo III: 800 (oitocentas) horas, prática pedagógica, assim distribuídas: a) 400 (quatrocentas) horas para o estágio supervisionado, em situação real de trabalho em escola, segundo o Projeto Pedagógico do Curso (PPC) da instituição formadora; e

b) 400 (quatrocentas) horas para a prática dos componentes curriculares dos Grupos I e II, distribuídas ao longo do curso, desde o seu início, segundo o PPC da instituição formadora. (BRASIL, 2019, p. 6, grifo nosso).

Como descrito no Art. $12^{\circ}$, o Grupo I, destinado à 800 horas do curso, será organizado pelas competências profissionais docentes, determinadas pelo conhecimento, prática e engajamento profissionais que comporão o currículo a partir das competências designadas pela BNCC: 
No Grupo I, devem ser tratadas ainda as seguintes temáticas: I - currículos e seus marcos legais: a) LDB, devendo ser destacado o art. 26-A; b) Diretrizes Curriculares Nacionais; c) BNCC: introdução, fundamentos e estrutura; e d) currículos estaduais, municipais e/ou da escola em que trabalha. II - didática e seus fundamentos [...] (BRASIL, 2019, p. 6).

O Grupo II, compreende o aprofundamento de estudos na etapa e/ou no componente curricular ou área de conhecimento e discorre que a carga horária de 1.600 horas deve efetivar-se do $2^{\circ}$ ao $4^{\circ}$ ano, de acordo com os três tipos de cursos, destinados à (BRASIL, 2019):

I - formação de professores multidisciplinares da Educação Infantil;

II - formação de professores multidisciplinares dos anos iniciais do Ensino Fundamental; e

III - formação de professores dos anos finais do Ensino Fundamental e do Ensino Médio (BRASIL, 2019, p. 7).

Este ponto se caracteriza em uma conjuntura ao dissociar o curso de Pedagogia, onde, de um lado, há um curso para formação da Educação Infantil, e de outro, a formação para os anos iniciais do Ensino Fundamental. No mesmo intento, no Capítulo VII, o Art. $22^{\circ}$ discorre que a formação de "[...] Administração, Planejamento, Inspeção, Supervisão e Orientação Educacional para a Educação Básica, nos termos do art. 64 da LDB, ou com centralidade em ambientes de aprendizagens e de coordenação e assessoramento pedagógico [...]", pode se dar em:

I - cursos de graduação em Pedagogia com aprofundamento de estudos nas áreas de que trata o caput e que possuam uma carga horária mínima de 3.600 (três mil e seiscentas) horas; e

II - cursos de especialização lato sensu ou cursos de mestrado ou doutorado, nas mesmas áreas de que trata o caput, nos termos do inciso II do art. 61 da LDB.

$\S 1^{\circ} \mathrm{O}$ aprofundamento de estudos de que trata o inciso I será correspondente a 400 (quatrocentas) horas adicionais às 3.200 (três mil e duzentas) horas previstas para o curso de Pedagogia (BRASIL, 2019, p. 11).

Tal organização reforça a divisão do curso de Pedagogia e reduz o currículo de conhecimentos, que antes eram inerentes à profissão. Além disso, nesse âmbito, a metade do curso será redigida especificamente para o domínio pedagógico da BNCC, que inclui os saberes específicos de "[...] conteúdos da área, componentes, unidades temáticas e objetos de conhecimento previstos pela BNCC e correspondentes competências e habilidades" (BRASIL, 2019, p. 9).

Assim, a BNCC torna-se um elemento regulador da formação de professores. $\mathrm{O}$ 
cenário caracteriza uma dissipação do curso com total controle curricular e significa que os professores serão formados exclusivamente para aplicar saberes práticos, pretendendo-se formar um professor pragmático, o que corrobora para que haja a perda do desenvolvimento intelectual docente e um retrocesso formativo.

A Resolução no 02/2019 é justamente a ação de alinhamento à BNCC que, de maneira interligada, conjectura a efetivação de um projeto educacional elaborado a partir de transições estrategicamente traçadas. Nesse sentido, é repleta dos interesses inerentes ao projeto de reformulação educacional previsto pela BNCC para os cursos de formação de professores, que determina um viés estritamente reduzido, técnico e prático para a formação inicial de professores da Educação Básica. Cabe, então, concordar que, a partir de lutas travadas, a visão tecnicista da profissão docente deve ser combatida, e o professor, reconhecido pelo inerente papel intelectual no seu trabalho. Porém, como a docência é um lócus de disputas políticas, as reformas educacionais podem ser uma ameaça e um desafio aos professores, recorrente a um cenário já antecedente na história da sociedade, pois, como desvenda Giroux (1997, p. 157),

Quando os professores de fato entram no debate é para serem objeto de reformas educacionais que os reduzem ao status de técnicos de alto nível cumprindo ditames e objetivos decididos por especialistas um tanto afastados da realidade cotidiana da vida em sala de aula.

A Resolução n 02/2019 preconiza uma reforma educacional caracterizada por uma concepção de formação docente estritamente ligada às competências, suscitando o princípio da docência por pressupostos que já haviam sido criticados e problematizados pelos estudiosos da área. $O$ que vemos na resolução é a visão de maneira muito expressiva do professor enquanto um técnico, conforme evidencia o seu Art. $2^{\circ}$ "A formação docente pressupõe o desenvolvimento, pelo licenciando, das competências gerais previstas na BNCC-Educação Básica" (BRASIL, 2019, p. 2, grifo nosso). Assim, instituindo a aplicabilidade da BNCC para a formação de professores, a partir de um currículo pautado sob um único viés, o das competências e habilidades, é apresentado o artigo $3^{\circ}$ do referido documento:

Art. $3^{\circ}$ Com base nos mesmos princípios das competências gerais estabelecidas pela BNCC, é requerido do licenciando o desenvolvimento das correspondentes competências gerais docentes. 
Parágrafo único. As competências gerais docentes, bem como as competências específicas e as habilidades correspondentes a elas, indicadas no Anexo que integra esta Resolução, compõem a BNC-Formação. (BRASIL, 2019, p. 2, grifo nosso).

Assim, é declarada uma redução da formação docente a um padrão predefinido da prática, que destitui o caráter intelectual formativo e desconsidera o desenvolvimento integral do licenciando em contramão de uma formação sólida, crítica e complexa. O que vemos é que este documento expressa que a formação de professores terá como princípios norteadores, além das competências gerais da BNCC, o desenvolvimento de competências gerais docentes da BNC, abrangendo as competências gerais e específicas, designadas pelo conhecimento profissional, pela prática profissional e pelo engajamento profissional com habilidades equivalentes (BRASIL, 2019). A noção de competências e habilidades minimiza o papel intelectual do professor, pois, como bem coloca Giroux (1997, p. 160),

As racionalidades tecnocráticas e instrumentais [...] desempenham um papel cada vez maior na redução da autonomia do professor com respeito ao desenvolvimento e planejamento curricular e o julgamento e implementação de instrução em sala de aula.

As competências e habilidades deslocam a formação docente para um viés instrumental, atingindo diretamente à docência ao restringir a autonomia do professor na tomada de decisões sobre o seu próprio trabalho, tornando-o um mero reprodutor de técnicas, o que contraria e desconsidera a intelectualidade do docente. Portanto, coadunamos com Giroux (1997) quando o autor defende os professores enquanto intelectuais e reflexivos, pois toda atividade humana é recorrente do pensamento. Ou seja, a ação docente baseada em determinações de competências exime a inteligência do professor e a imprescindível integração do pensamento para a relação teoria e prática.

Para Giroux (1997, p. 161), é inerente que:

[...] ao argumentarmos que o uso da mente é uma parte geral de toda atividade humana, nós dignificamos a capacidade humana de integrar o pensamento e a prática, e assim destacamos a essência do que significa encarar os professores como profissionais reflexivos [...]

A formação docente só é íntegra quando o professor é formado para refletir sobre a prática, e não somente para aplicar competências estabelecidas. Uma formação com essa base retira o professor do processo de centralidade e afasta a sua intelectualidade, que compele o caráter instrumental e técnico e denota uma redução do trabalho docente. Fica 
expresso que, mesmo se referindo aos conhecimentos do curso, a base comum é que a norteia, e a metade do curso destina-se para o domínio do que tange à BNCC estritamente em competências e habilidades, contrapondo a importância da amplitude em que permeia a educação. Entretanto, a profissão atividade docente não se limita a técnicas.

Se acreditarmos que o papel do ensino não pode ser reduzido ao simples treinamento de habilidades práticas, mas que, em vez disso envolve a educação de uma classe de intelectuais vital para o desenvolvimento de uma sociedade livre, então a categoria de intelectual torna-se uma maneira de unir a finalidade da educação de professores, escolarização pública e treinamento profissional aos próprios princípios necessários para o desenvolvimento de uma ordem e sociedade democráticas. (GIROUX, 1997, p. 162, grifo nosso).

Reduzir a formação de professores e o trabalho docente a competências e habilidades técnicas é coibir a capacidade intelectual e descaracterizar a docência. É dissociar o que é indissociável da formação docente sólida. Ao incluir as "1.600 horas de aprofundamento desses cursos os seguintes saberes específicos: conteúdos da área, componentes, unidades temáticas e objetos de conhecimento previstos pela BNCC e correspondentes competências e habilidades" (BRASIL, 2019, p. 9, grifo nosso), é reafirmada a base da formação docente a partir de saberes específicos da BNCC, ressaltando, pois, as competências e habilidades que, para Giroux (1997), desmontam o vital fundamento de incorporar os professores como intelectuais, assim:

[...] fornece uma vigorosa crítica teórica das ideologias tecnocráticas e instrumentais subjacentes à teoria educacional que separa a conceitualização, planejamento e organizado curricular dos processos de implementação e execução. (GIROUX, 1997, p. 161).

Ao impor uma ideologia tecnocrática e instrumental para a educação, a resolução define um currículo intransigente que impossibilita a participação ativa do professor ao que diz respeito ao seu próprio trabalho, limitando-o a apenas à aplicação de um currículo posto, já que "[...] muitas das recomendações que surgiram no atual debate ignoram o papel que os professores desempenham na preparação dos aprendizes para serem cidadãos ativos e críticos [...]" (GIROUX, 1997, p. 157).

As evidentes competências e habilidades negam os professores enquanto intelectuais, reduzindo-os à função de competências e habilidades ao colocarem em prática instruções impostas para a aplicabilidade da BNCC e, consequentemente, a BNCFormação. Como sublinha Giroux (1997), os professores possuem responsabilidade sobre 
o seu trabalho, mas é impossível que isso de fato ocorra se forem coagidos por uma divisão completa de trabalho, pois "[...] este ponto tem uma dimensão normativa e política que parece especialmente relevante para os professores [...]" (GIROUX, 1997, p. 162).

Enquanto a Resolução $n^{\circ}$ 02/2019 impõe uma formação docente e um currículo baseado em competências por uma lógica de padronização, tornando o professor um tarefeiro, com um trabalho técnico, e não reflexivo, contrariamente, a formação docente sólida visa e possibilita um professor intelectual e ativo, pois "[...] os professores deveriam se tornar intelectuais transformadores se quiserem educar os estudantes para serem cidadãos ativos e críticos [...] (GIROUX, 1997, p. 163). Por conseguinte, a aplicabilidade da resolução a partir de competências e habilidades leva à formação docente simplista e esvaziada da intelectualidade, tornando a profissão docente uma técnica aplicável.

\section{Considerações Finais}

O presente artigo alinha-se ao cenário atual de reforma educacional diante das imposições lançadas na educação brasileira a partir da Resolução n 02/2019, que altera a formação de professores da Educação Básica. Nesse sentido, inferimos que a resolução alinha a formação docente para uma estrita reprodução de competências impostas pela BNCC e BNC-Formação, o que retira os professores da centralidade de seu trabalho e restringe a intelectualidade da profissão docente, passando para um trabalho técnico e instrumental.

Verificamos que, além das competências, a concepção de formação docente da resolução transpassa o praticismo e o utilitarismo, pois sobreleva a prática e minimiza a teoria. Tal situação leva à uma padronização do trabalho docente e à redução da prática para o sentido utilitário a partir do domínio de conteúdos e conhecimentos técnicos. Assim, a concepção de formação docente contida nos excertos do documento demonstra um viés técnico, praticista e utilitarista.

A perspectiva de formação docente presente na Resolução n 02/2019 desconsidera todo o percurso histórico e os princípios de uma sólida formação de professores, envergando a educação brasileira para um indistinguível retrocesso que implica na precarização do trabalho docente. 
Este projeto de educação está repleto de preceitos que reduzem e colocam a profissão docente em risco. Fica evidente, então, que existe um lastro teórico na proposta da resolução, que conduz à centralidade da formação de professores em competências.

Não obstante, o documento apresenta que a formação docente deve ter foco na prática para corresponder às demandas atuais, aos resultados de aprendizagem e ao ensino de habilidades e competências esperadas pela BNCC. Composta pela manifestação de ideias retroativas, traz uma completa depreciação da inteligência docente e subalterniza o professor a um sistema de controle que inibe as perspectivas da docência conforme exposto pelas autoras (RODRIGUES; PEREIRA; MOHR, 2020).

Chama a atenção ainda que, no contexto da Resolução no 02/2019, são as três esferas de poder (OM, APH e AE), situadas por Evangelista (2021), que atuam sobre a escola como processos mediadores que submetem o professor como um instrumento dos interesses do capital. A implementação da BNCC e a aprovação da BNC-Formação não são processos divergentes, mas peças que compõem uma complexa engrenagem e que retiram do professor o controle sobre o seu trabalho.

\section{Referências}

AULA Inaugural 2021 - PPGE/UFJ com Profa. Dra. Olinda Evangelista. [S. I.: s. n.], 2021. 1 vídeo (130 min). Publicado pelo Canal PPGE UFJ. Disponível em: https://www.youtube.com/watch?v=m5RQt4ivpbY. Acesso em: 5 out. 2021.

BRASIL. Resolução CNE/CP N o 2, de 22 de dezembro de 2017. Institui e orienta a implantação da Base Nacional Comum Curricular, a ser respeitada obrigatoriamente ao longo das etapas e respectivas modalidades no âmbito da Educação Básica. Diário Oficial da União: seção 1, Brasília, DF, n. 245, p. 41-44, 22 dez. 2017.

BRASIL. Resolução de CNE/CP № 2, de 20 de dezembro de 2019. Define as Diretrizes Curriculares Nacionais para a Formação Inicial de Professores para a Educação Básica e institui a Base Nacional Comum para a Formação Inicial de Professores da Educação Básica. Diário Oficial da União: seção 1, Brasília. DF, p. 87-90, 10 de fevereiro de 2020.

BRZEZINSKI, I. Políticas Contemporâneas de formação de professores para os Anos Iniciais do Ensino Fundamental. Educ. Soc, Campinas, v. 29, n. 105, p. 1139-1166, set./dez. 2008.

GIROUX, H. A. Os professores como intelectuais: rumo a uma pedagogia crítica da aprendizagem. Porto Alegre: Artes Médicas, 1997. 
NÓVOA, A. Formação de professores e profissão docente. In: Professores e a sua Formação. Lisboa: Editora Dom Quixote, 1992. (Org.). Os

RODRIGUES, L. Z; PEREIRA, B.; MOHR, A. O Documento "Proposta para Base Nacional Comum da Formação de Professores da Educação Básica" (BNCFP): Dez Razões para Temer e Contestar a BNCFP. Revista Brasileira de Pesquisa em Educação em Ciências, [s. I.], v. 20, p. 1-39, janeiro/ dezembro. 2020. DOI: 10.28976/19842686rbpec2020u139. Disponível em:

https://periodicos.ufmg.br/index.php/rbpec/article/view/16205. Acesso em: 5 out. 2021.

RODRIGUES, L. Z; PEREIRA, B.; MOHR, A. Recentes Imposições à Formação de Professores e seus Falsos Pretextos: as BNC Formação Inicial e Continuada para Controle e Padronização da Docência. Revista Brasileira de Pesquisa em Educação em Ciências, v. 21, p. 1-39, janeiro/ dezembro.2021. DOI:10.28976/19842686rbpec2021u12771315. Disponível em: https://periodicos.ufmg.br/index.php/rbpec/article/view/35617. Acesso em: 10 nov. 2021

TARDIF, M. Saberes docentes e formação profissional. 17. ed. Petrópolis, RJ: Vozes, 2014.

XX ENCONTRO NACIONAL DA ANFOPE, 2021, ANFOPE. "Política de formação e valorização dos profissionais da educação: Resistências propositivas à BNC da Formação inicial e continuada", 2021.

\section{NOTAS}

\section{IDENTIFICAÇÃO DE AUTORIA}

Flavia Wegrzyn Magrinelli Martinez. Mestre e Doutora em Educação pela Universidade Estadual de Ponta Grossa (UEPG). Professora do Curso de Pedagogia da Universidade Estadual do Norte do Paraná (UENP), Centro de Ciências Humanas e da Educação- CCHE/Colegiado de Pedagogia, Campus de Jacarezinho,

Paraná, Brasil.

E-mail: fwmartinez@uenp.edu.br

(iD) https://orcid.org/0000-0003-3540-4032

Nathalia Cristina Vidal. Acadêmica do curso de Pedagogia da Universidade Estadual do Norte do Paraná, Campus de Jacarezinho, PR, Brasil

E-mail: nathaliavidal@outlook.com

(iD) https://orcid.org/0000-0001-8969-3453

Analígia Miranda da Silva. Mestre e Doutora em Educação pela Universidade Estadual Paulista (UNESP/FCT). Professora adjunta na Universidade Federal de Mato Grosso do Sul (UFMS), Campus do Pantanal (CPAN), Corumbá, MS, Brasil.

E-mail: analigia.miranda@ufms.br

(i) https://orcid.org/0000-0002-3232-323X

\section{AGRADECIMENTOS}

Não se aplica.

\section{FINANCIAMENTO}

Não se aplica. 


\section{CONSENTIMENTO DE USO DE IMAGEM}

Não se aplica.

\section{APROVAÇÃO DE COMITÊ DE ÉTICA EM PESQUISA}

Não se aplica.

\section{LICENÇA DE USO}

Autores mantêm os direitos autorais e concedem à revista ENSIN@ UFMS - ISSN 2525-7056 o direito de primeira publicação, com o trabalho simultaneamente licenciado sob a Licença Creative Commons Attribution (CC BY-NC-SA 4.0), que permite compartilhar e adaptar o trabalho, para fins não comerciais, reconhecendo a autoria do texto e publicação inicial neste periódico, desde que adotem a mesma licença, compartilhar igual.

\section{EDITORES}

Patricia Helena Mirandola Garcia, Eugenia Brunilda Opazo Uribe, Gerson dos Santos Farias.

\section{HISTÓRICO}

Recebido em: 20/11/2021 - Aprovado em: 04/12/2021 - Publicado em: 06/12/2021.

\section{COMO CITAR}

MARTINEZ, F. W. M; VIDAL, N. C; SILVA, A. M. Reflexões sobre os Impactos da Resolução No 02/2019 na

Formação Inicial Docente. Revista ENSIN@ UFMS, Três Lagoas, v. 2, n. 6, p. 115-132. 2021. 